\title{
Lesões bolhosas palmo-plantares pós-quimioterapia
}

\section{Palmar-Plantar Erythrodysesthesia after Chemotherapy}

Apresentamos um caso de um doente com o diagnóstico de sarcoma pulmonar que, após $03^{\circ}$ ciclo de tratamento com doxorrubicina lipossómica pegilada (DLP) $\left(50 \mathrm{mg} / \mathrm{m}^{2}\right.$ cada 4 semanas), desenvolveu exuberantes lesões bolhosas, descamativas, nas palmas das mãos, (Figuras 1 e 2), e plantas dos pés, com impotência funcional total. Efetuou-se tratamento com corticoide sistémico e aplicação tópica de antibiótico, corticoide e hidratantes. Após duas semanas a melhoria em termos de dor e capacidade funcional foram substanciais (Figuras 3 e 4). Devido à severidade deste episódio, nos tratamentos subsequentes a DLP foi substituída por trabectidina.

A eritrodisestesia palmo-plantar ${ }^{1}$, também conhecido por síndrome palmo-plantar ou eritema acral é uma reacção de toxicidade cutânea, induzida por várias drogas usadas em quimioterapia. As mais frequentes são a capecitabina, DLP e fluorouracilo. 0 mecanismo exacto de patogenicidade não é bem conhecido. $50 \%$ dos doentes que recebem DLP (50mg/m² cada 4 semanas) desenvolvem 0 síndrome.

A severidade dos sintomas varia desde um ligeiro eritema (Grau 1) até toxicidade severa com lesões bolhosas, descamativas, muito dolorosas (Grau 3), que impossibilitam por completo a realização das actividades da vida diária. As principais medidas terapêuticas são a suspensão do fármaco e tratamento sintomático para controlo da dor, edema e prevenir sobreinfecção. A aplicação local de frio pode ajudar a prevenir as lesões, pela diminuição do fluxo sanguíneo cutâneo², assim como a administração de piridoxina e corticoide oral. A solução de Dimetilsulfóxido (DMSO) pode ser usada como tratamento tópico ${ }^{3}$. Consoante a severidade, nos tratamentos de quimioterapia subsequentes, pode ser necessário reduzir a dose do fármaco ou ponderar a adopção de um esquema terapêutico alternativo².

\section{Bibliografía}

1. Lokich JJ, Moore C. Chemotherapy-associated palmar-plantar erythrodysesthesia syndrome. Ann Intern Med. 1984; 101(6): 798-9.

2. Lorusso D, Di Stefano A, Carone V, Fagotti A, Pisconti S, Scambia G. Pegylated liposomal doxorubicin-related palmar-plantar erythrodysesthesia ('hand-foot' syndrome). Ann Oncol. 2007; 18(7):1159-64.

3. Clark AS, Vahdat LT. Chemotherapy-induced palmar-plantar erythrodysesthesia syndrome: etiology and emerging therapies. Support Cancer Ther. 2004;1(4): 213-8.

\section{Diagnóstico}

Eritrodisestesia Palmo-Plantar

Mário Pires, Magda Sousa

Serviço de Medicina Interna. Centro Hospitalar do Baixo Vouga. Aveiro. Portugal

Como citar este artículo: Pires M, Sousa $M$

Lesões bolhosas palmo-plantares pós-quimioterapia. Galicia Clin 2013; 74 (3): 143

Recibido: 5/3/2013; Aceptado: 11/4/2013

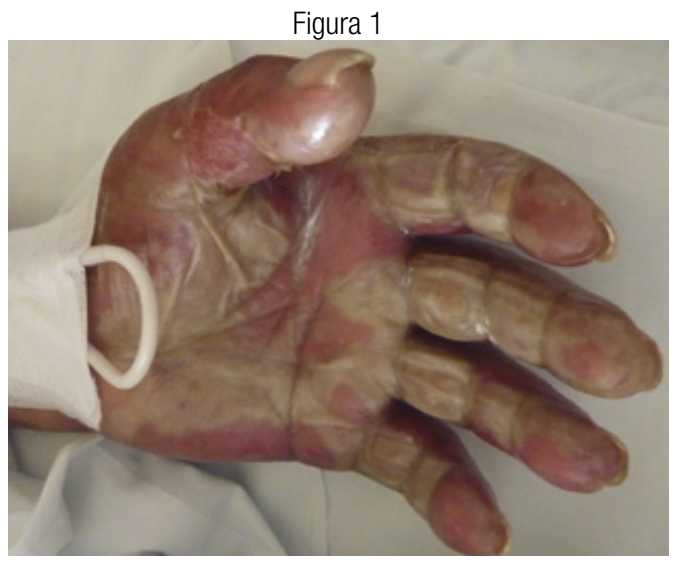

Figura 2

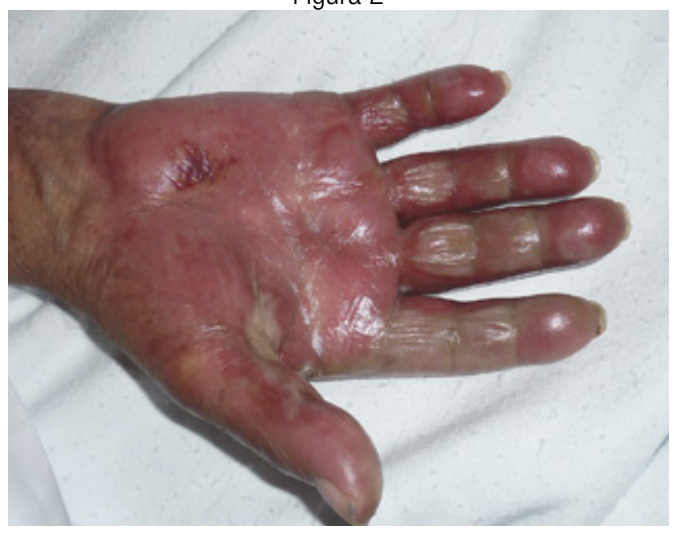

Figura 3

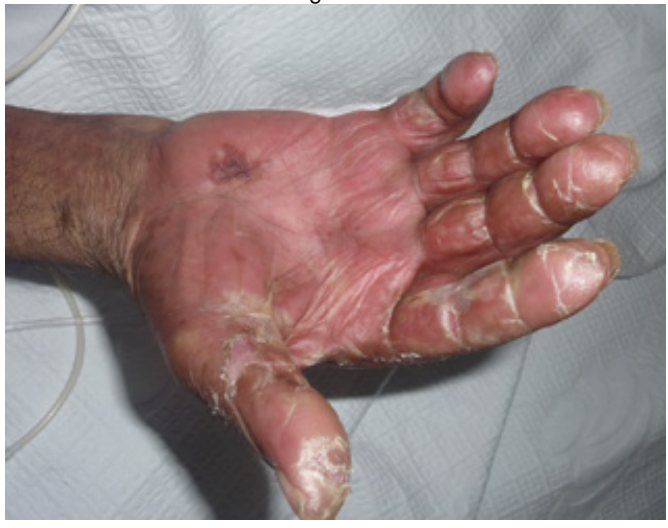

Figura 4

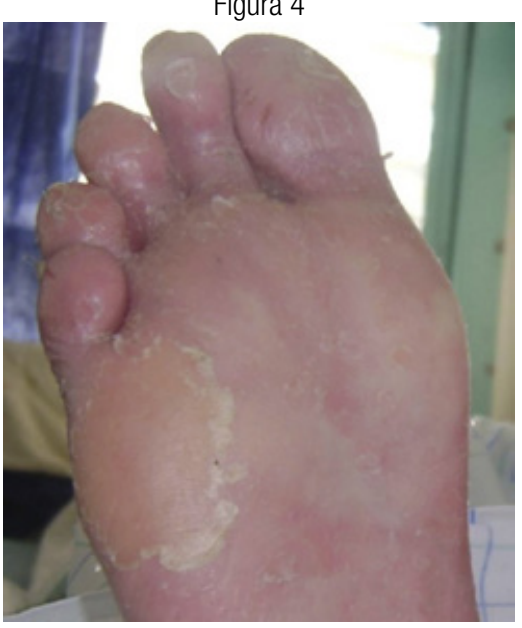

